\title{
A FRAMEWORK FOR GEOGRAPHIC OBJECT-BASED IMAGE ANALYSIS (GEOBIA) BASED ON GEOGRAPHIC ONTOLOGY
}

\author{
H. Y. Gu ${ }^{\text {a }}$ *, H.T. Li ${ }^{\text {a }}$ L. Yan ${ }^{\text {b }}$, X.J. Lu ${ }^{c}$ \\ ${ }^{a}$ Key Laboratory of Geo-Informatics of State Bureau of Surveying and Mapping, Chinese Academy of Surveying and Mapping, 28 \\ Lianhuachi Road, P.R. China - (guhy,lhtao)@casm.ac.cn \\ ${ }^{\mathrm{b}}$ School of Geodesy and Geomatics, Wuhan University, Luojiashan, P.R. China - lyan@ @sgg.whu.edu.cn \\ ${ }^{c}$ Institute of Geographic Sciences and Natural Resources Research, Chinese Academy of Sciences, 11 Datunlu, P.R.China -
}

Luxj@lreis.ac.cn

\section{Commission VI, WG VI/4}

KEY WORDS: Geographic Object-Based Image Analysis, Geographic Ontology, Semantic Network Model, Ontology Web Language

\begin{abstract}
:
GEOBIA (Geographic Object-Based Image Analysis) is not only a hot topic of current remote sensing and geographical research. It is believed to be a paradigm in remote sensing and GIScience. The lack of a systematic approach designed to conceptualize and formalize the class definitions makes GEOBIA a highly subjective and difficult method to reproduce. This paper aims to put forward a framework for GEOBIA based on geographic ontology theory, which could implement "Geographic entities - Image objects Geographic objects" true reappearance. It consists of three steps, first, geographical entities are described by geographic ontology, second, semantic network model is built based on OWL(ontology web language), at last, geographical objects are classified with decision rule or other classifiers. A case study of farmland ontology was conducted for describing the framework. The strength of this framework is that it provides interpretation strategies and global framework for GEOBIA with the property of objective, overall, universal, universality, etc., which avoids inconsistencies caused by different experts' experience and provides an objective model for mage analysis.
\end{abstract}

\section{INTRODUCTION}

GEOBIA (Geographic Object-Based Image Analysis) is not only a hot topic of current remote sensing and geographical research. It is believed to be a paradigm in remote sensing and GIScience (Blaschke et al.,2010; Blaschke,2014). It aims to develop automated methods for partitioning remote sensing (RS) imagery into meaningful image objects, and to assess their characteristics through spatial, spectral, textural, and temporal features, thus generating new geographic information in a GISready format (Blaschke et al.,2010). Advances in GEOBIA research over the last decade have led to the development of dedicated software packages and a sharp increase in the number of associated peer-reviewed papers published in scientific journals. Four biennial international GEOBIA conferences have now been successfully held and various other events have also contributed to the growing number of books and proceedings available in this field, while the number of relevant university courses held and theses prepared has also increased significantly(Addink, Van Coillie, and De Jong, 2012; Blaschke, 2010). In addition, there is now a GEOBIA wiki used to promote international exchange and development. It has been widely applied in environmental monitoring, agricultural development, and natural resource management applications, as well as in defence and security applications $(\mathrm{Pu}$, Landry and $\mathrm{Yu}$, 2011; Hussain et al. 2013; Blaschke et al. 2011; Nussbaum and Menz,2008).

Although GEOBIA shows outstanding advantages, several challenges exist. One of these challenges is that the interpretation results may be inconsistent when utilizing different rulesets and expert knowledge. Consequently, the lack of a systematic approach designed to conceptualize and formalize the class definitions makes GEOBIA a highly subjective and difficult method to reproduce (Arvor et al. 2013; Belgiu, Dră guț, and Strobl, 2014).

Ontologies offer considerable potential to conceptualize and formalize the a priori knowledge about evaluated domain categories (Lüscher, Weibel, and Burghardt, 2009). In the Artificial Intelligence (AI) domain, ontology is defined as a formal, explicit specification of a shared conceptualization (Gruber,1993). It is used as solution to organize and to express the domain knowledge into a machine-readable format.

It has been proposed as solution to represent consensual domain knowledge in a formal and machine-readable notation (Gruber,1993). It has been used in geography domain for semantic modelling, semantic interoperability, and knowledge sharing and reuse (Agarwal, 2005; Andres, 2012; Mark et al., 2005). Several works focused on applying ontology in remote sensing domain. Yue et al.(2013)presented intelligent services for discovery of complex geospatial features from remote sensing imagery. Andres et al.(2012)described how to use ontology to improve the level of automation. Arvor et al. (2013) analysed the potential applications of GEOBIA in remote sensing data discovery, multi-source data integration, image interpretation, workflow management, knowledge sharing. Jesús et al.(2013) built a framework for ocean image classification based on ontologies, which described how low and high level content of ocean satellite images can be modeled with an ontology. In addition, decision tree based classifiers and rule-based expert systems are represented. Dejrriri et al.(2012)

\footnotetext{
* Corresponding author
} 
present GEOBIA and data mining techniques for non-planned city residents based on ontology. Forestier et al. (2013) built Coastal Zone ontology to extract Coastal Zone with background and semantic knowledge. Kyzirakos et al. (2014) provided wildfire monitoring services combined Satellite images, geospatial data with ontology. Belgiu, M. (2014) presented a ontology-based classification method for building types where Airborne Laser Scanning Data are used. Cui W.(2013) presented a GEOBIA method based on Geographic Ontology and relative elevation. Belgiu, Hofer, and Hofmann (2014) presented a method to automatically integrate ontologies in OBIA, which reduces the effort necessary to define the classes for image analysis and simultaneously reduces its subjectivity.

Despite their potential for image interpretation, geographic ontology is yet rarely used by the GEOBIA community, and it still belongs to the category of pattern recognition in essence and cannot reach to the objective recognition of geographic objects. The reason might be that we lack the research of GEOBIA process from the geographic ontology view.

This paper puts forward a framework for GEOBIA based on geographic ontology theory, which could implement " Geographic entities - Image objects - Geographic objects " true reappearance. With this aim, we will describe geographical object by geographic ontology, furthermore, we will show how the image classification can be modelled with the ontology. Then we will describe object classification based on classification model. At last, we explain our framework through a use case of farmland ontology.

\section{GEOBIA FRAMEWORK BASED ON GEO- ONTOLOGY}

\subsection{A new GEOBIA framework based on geo-ontology}

General GEOBIA is an iterative image classification method that begins with the partition of the imagery into homogenous image objects by means of segmentation algorithms. Once the image objects are created, the operator develops rulesets to assign image objects to the desired categories, the classification is expected to be biased by operator's subjectivity (Belgiu,2015). A new GEOBIA framework based on geoontology is that the geographical entity is described from the Geo-ontology view at first, then a semantic network model is established, at last, image object are classified based on the semantic network and hybrid learning.

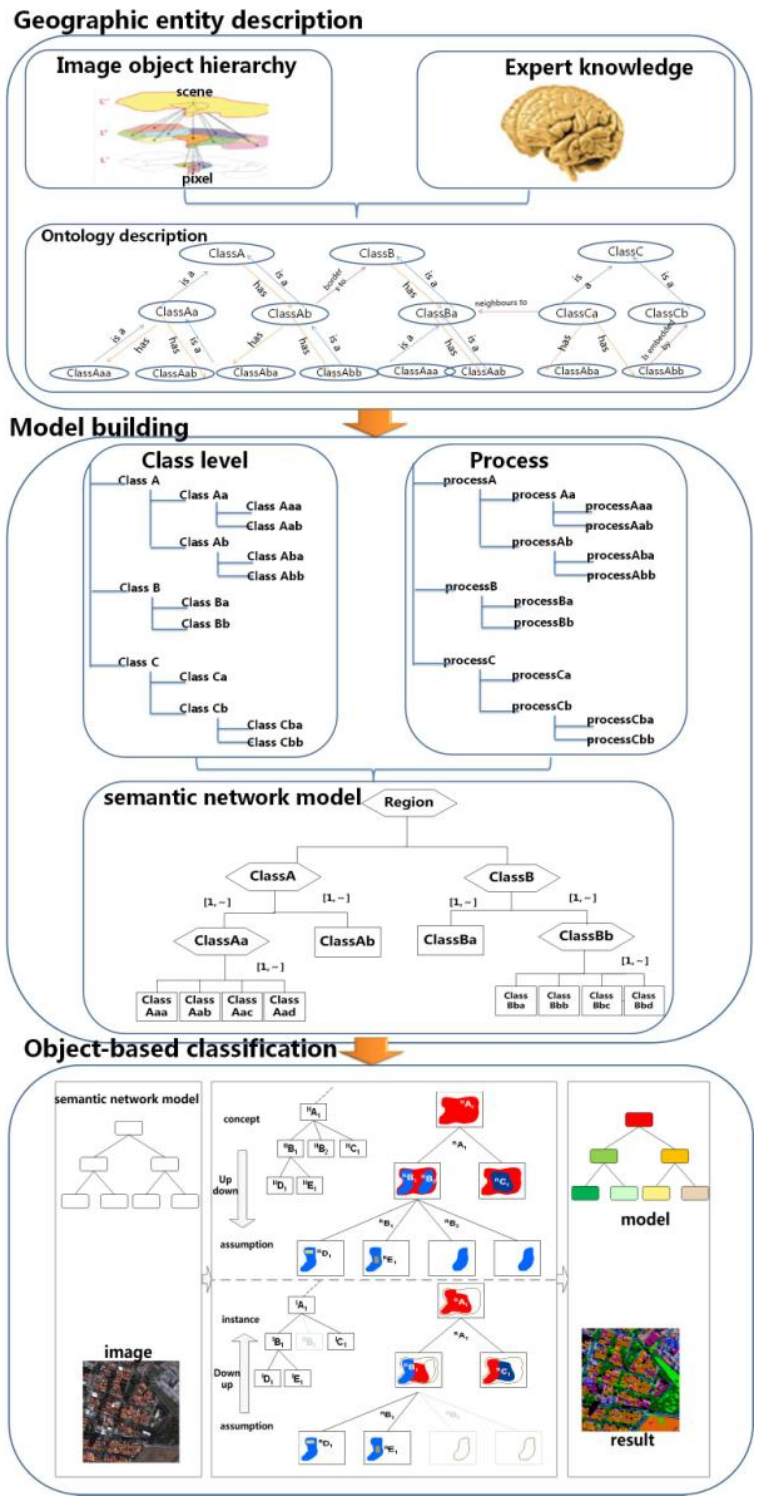

Figure 1. Geographic ontology driven GEOBIA framework

Step 1: Geographic entity description. Objective quantitative features and the subjective domain expert's knowledge are established using geographic ontology.

Step 2: Model building. Analysis category level and processing, semantic network knowledge representation modelled based on the geographic ontology.

Step 3: Object-based classification. Based on semantic network model, it realizes the object-based classification based on hybrid learning.

The new framework realizes a real appearance of "Geographic entities - Image objects - Geographic objects", which has the following advantages: (1) It could provide interpretation strategies and global framework for GEOBIA with the property of objective, overall, universal, universality, etc.; (2) It uses geo-ontology to link image objective characteristics and subjective knowledge experts, which could avoid inconsistencies caused by different experts' experience. (3) It could express objective concept, feature, and relationship obviously, and reduce the semantic gap between low-level features and high-level features, and is easy to articulate semantic relations in computer operable formal language; (4) It uses hybrid learning with up to down model and down to up model in the cognitive interpretation mode, which could not 
only reflect the geographical objects of remote sensing image interpretation results, but also verify and validate the semantic network model, and it could provide a reference model for similar area and similar data.

\subsection{Geographic entity description}

Geographic entity description is the basis for modelling, which describes concept and relationship of geographic entity, and links the quantitative and qualitative knowledge, and expresses geographic object formally. It could improve the robustness of the expression of geographic object, and ensure that the knowledge of geographic objects are consistent, thus avoids the inconsistent of different expert knowledge.

The steps are as followings: first, the concept of geographic entity is built; second, the domain knowledge is created; at last, the ontology concept model is created. The concept of geographic entity is described by common concept, which has its own intension and extension, and reflects the thinking form of the essential attribute of an object. The domain knowledge includes geographic knowledge, remote sensing imagery, image object feature, and auxiliary data (Figure 1). Ontology concept model is the use of domain knowledge to express geographic object with its conceptualization and clarity features.

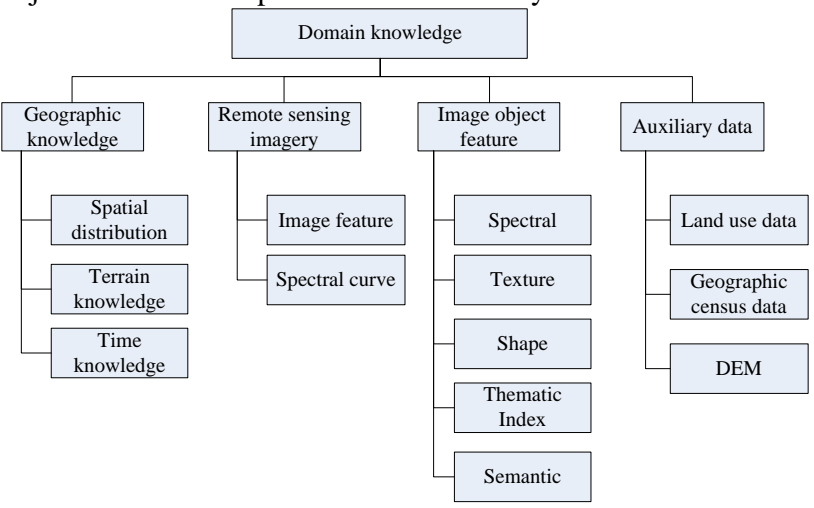

Figure 2. domain knowledge of remote sensing

\subsection{Model building}

The model is built based on the geographic entity description. The methods of knowledge description include production, frames, semantic network, neural networks, etc. which has its own advantage.

Semantic network model is a network diagram, where, the knowledge is expressed by concept, feature, and rule. (Figure 2)

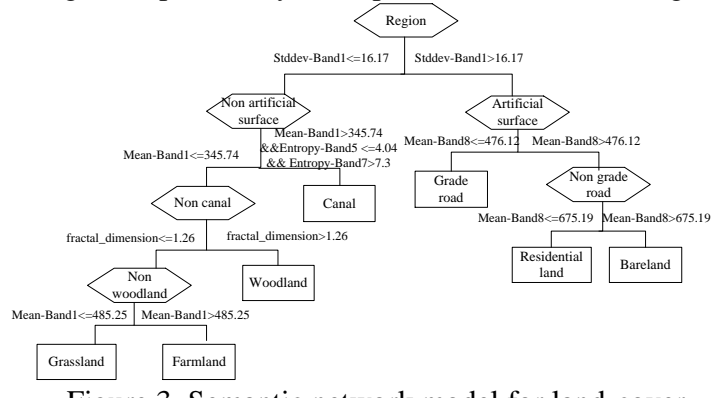

Figure 3. Semantic network model for land-cover

Nodes represent a variety of things, concepts, condition, attributes, actions, status; Arcs represent various semantic relationships between nodes; the nodes and connections with the logo used to distinguish various relationships between different objects.

Multiple sources data such as remote sensing image, vector, GIS data, and priori knowledge could integrate at different scales. Different scales have easy relationships such as Is-a, A-
Kind-of, A-Member-of, Instance-of, Part-of, Composed-of etc. and has advanced relationships such as conjunctions, disjunction, negation, implication and quantization etc.

Semantic network has the following advantages: (1) It could link and express various features explicitly, which reducing the semantic gap between low-level features and advance semantic features; (2) It could trace parent object, child object, and neighborhood object by contacting the relevant geographic object;(3) It is easy to articulate geographic object concept and their semantic relations in computer-actionable formal language. Definiens software is a successful example of knowledge expression with a semantic network model. But it lacks the approach to conceptualize and formalize the class definitions and rulesets which makes it a highly subjective and difficult method to reproduce.

The semantic network model could be expressed by Web Ontology Language (OWL), which is stronger than XML, RDF and RDF Schema (RDF-S) in the term of machine comprehensibility.

\subsection{Image Object classification}

The image object is classified with machine learning methods (such as random forests, deep learning, artificial immune systems, etc.) based on semantic network model and hybrid (top-down, bottom-up)control tactics. It has two steps:

Top-down: it generates assumptions of objects through the implementation of top-down operators and decision rules.

Bottom-up: validate or discard assumptions of objects by the decision rules, thus instances of objects are created.

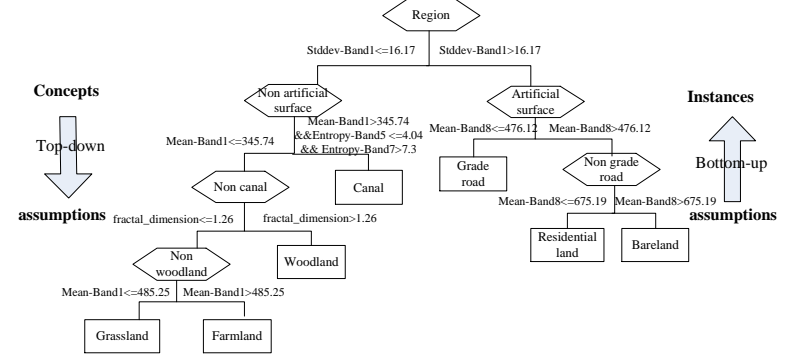

Figure 4. Hybrid control tactics based on semantic network model

The method could not only reflect the geographical objects, but also verify and validate the semantic network model. Even more, it could provide a reference model for similar area and similar data with its traceability and credibility.

\section{A USE CASE- FARMLAND ONTOLOGY}

\subsection{Farmland description}

The quantity and quality of farmland affect the national food security. Obtaining accurate farmland information is the basis for protecting the farmland resources. This chapter discusses this research framework, takes farmland extraction for example. We reviewed the geographical and remote sensing literature for defining farmland ontology based on visual interpretation from aerial photographs or satellite imagery. 
3.1.1 The concept of farmland: Concept 1 (GDPJ 01-2013): Farmland is often cultivated for planting crops, which includes cooked farmland, new developed farmland and grass crop rotation land; It is mainly for planting crops, and there are scattered fruit trees, mulberry trees or others (forest coverage is generally $50 \%$ or less). It also includes plastic shed covered land. The temporal arable land and professional garden are not as farmland.

Concept 2(GB/T 21010-2007): Farmland is often cultivated for planting crops, which includes cooked farmland, new developed farmland and grass crop rotation land; It includes floodplain and wetland which could ensure cultivate once a year, and includes ditch, drainage, roads and sill with width $<1.0 \mathrm{~m}$ for southern, width $<2.0 \mathrm{~m}$ for northern.

The concepts of farmland are the same basically, but there has difference types.

\subsubsection{Farmland Domain knowledge:}

\section{1) Geographic knowledge}

(1) Spatial distribution of farmland

The spatial distribution feature could help us to understand the distribution of farmland from the macro perspective view.

Farmland of China can be divided into highly sparse areas, low sparse areas, the general transition zone, low concentration, high concentration area. $88 \%$ farmland of China is distributed in the $40 \%$ area to the Southeast of Hu HuanYong line.

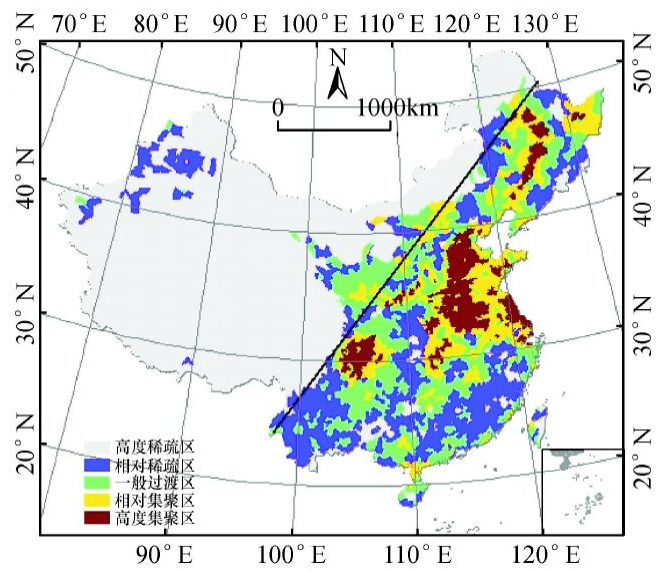

Figure 5. Farmland Spatial distribution of China in 2000

\section{(2) Terrain knowledge}

The terrain knowledge can help us to understand the spatial and the fragmentation of plaque. The bigger the slope is, the greater the degree of fragmentation. Farmland is mainly distributed on both sides of the rivers, where the area is suitable for farming with adequate water, fertile soil and convenient transportation.

\section{(3)Time knowledge}

The time knowledge can help us to reflect the variation of the feature itself with seasonal. And determine the types and features of farmland when combined with the use of farming calendar. There are three stages: 1) in the early August to late September, Farmland is covered, and it is not yet begun harvesting; 2) in the early October to late October, at the crop harvest stage, farmland is covered or uncovered; and 3) in early November to next January, farmland is uncovered.

\section{2) Remote sensing imagery}

\section{(1) Image feature}

Table 1. Image feature information

\begin{tabular}{|l|l|l|}
\hline $\begin{array}{l}\text { Feature } \\
\text { Name }\end{array}$ & Type & Explanation \\
\hline Sensor & text & $\begin{array}{l}\text { Such as QuickBird, } \\
\text { WorldView }\end{array}$ \\
\hline
\end{tabular}

\begin{tabular}{|l|l|l|l|}
\hline $\begin{array}{l}\text { Spatial } \\
\text { resolution }\end{array}$ & Number & $0.5-5 \mathrm{~m}$ & \\
Year & Number & - & \\
$\begin{array}{l}\text { Month } \\
\text { Band }\end{array}$ & Number & $1-12$ \\
combination & Number & $\begin{array}{l}\text { Such as band 1,band } \\
2, \text { band 3 }\end{array}$ \\
\hline
\end{tabular}

\section{(2) Spectral curve}

Spectral curve reflects electromagnetic reflection and emission characteristics of different bands.

The Hue of farmland is relatively uniform, and intensity change in the flat space is relatively slow. In different seasons, due to different crops, farmland will show different colour characteristics. And it will become to barren land when there is no planting crop, then its tone will become uniform. Therefore, the spectral curve of farmland will generally change with time.

3) Image object features

\section{(1)Spectral features}

Spectral features including the mean, variance, maximum, minimum, saturation, hue, and brightness, which provide the most important information; additional features can also be derived from the spectral characteristics.

\section{(2) Textural features}

Textural features reflect the spatial variation of the gray value. The texture of farmland is relatively smooth which depends largely on the crop leaf shape, size and shadows. The texture is described with Gray Level Co-occurrence Matrix (GLCM) such as Entropy, Energy, Contrast etc. Entropy is a measure of the randomness of image information and expression, which describes the complexity of gradation change; Energy also known as Angular Second Moment(ASM), which can measure the thickness of texture and the uniformity of gray level; Correlation is used to describe the degree of similarity between elements of rows or columns, it reflects some gray value level extending certain direction, the longer it extends, the greater the relevance is; Homogeneity reflects the uniformity of the region, the greater its value, the uniformity the region is; Contrast reflects the strength of the texture and the clarity of the image, the higher it is, the more obvious the texture is.

\section{(3)Shape features}

Shape features reflect the geometric shape of objects. Area, perimeter, aspect ratio, width, length and shape index are the most important spatial features.

\section{(4) Thematic index}

Thematic index can be used to characterize or to highlight one or more feature types. Farmland is represented by NDVI(Normalized Difference Vegetation Index), RVI(Ratio Vegetation Index), DVI(Difference Vegetation Index), SAVI(the Soil Adjusted Vegetation Index), etc.

\section{(5) Semantic Features}

Semantic Features reflect the spatial distribution of surface features and space arrangement. It can be divided into absolute position, relative position, neighbour relations, disjoint relations and containment relations. Because the presence of the bright ridge line between the fields, it would help to identify and extract farmland effectively.

\section{3) Auxiliary data}

Land use data and Geographic census data are the auxiliary data, these data can be used to assist in image interpretation and sample selection, and superimposed with the classification result to optimize the classification results.

In addition, DEM, slope, water, transportation, residential and other data can be assisted in the extraction of farmland.

4) Summary 
The farmland domain knowledge includes geographic knowledge, remote sensing imagery, image object feature, and auxiliary data. Geographic knowledge can grasp the macro spatiotemporal layout, and guide the extraction of farmland. Remote sensing imagery can play the role of Contents Index when extracting farmland using high resolution image. Image object feature can be used as a source of knowledge directly. Auxiliary data can assist in the extraction and optimization of farmland.

\subsubsection{Farmland concept model}

The farmland concept model in Geographic National Condition Census is shown in figure 6.

Farmland belongs to Vegetation, and it has the typical features, such as smooth, regular, has bright ridge, near to rivers, etc.

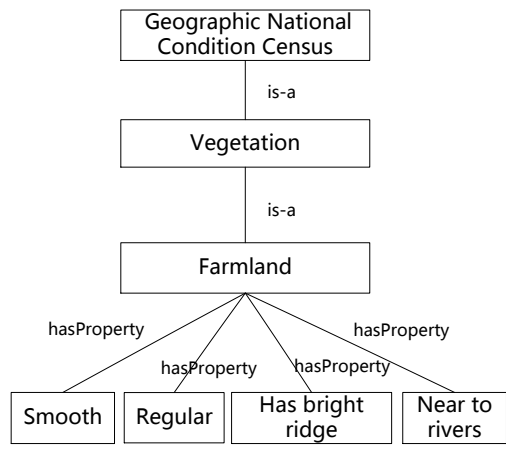

Figure 6. Farmland concept model.

\subsection{Farmland semantic network model}

Ontologies are used to capture knowledge about some domain of interest. An ontology describes the concepts in the domain and also the relationships that hold between those concepts. Different ontology languages provide different facilities. The most recent development in standard ontology languages is OWL from the World Wide Web Consortium(W3C). (http://www.w3.org/TR/owl-guide/) Like Protégé, OWL makes it possible to describe concepts but it also provides new facilities.

An OWL ontology consists in Individuals, Properties, and Classes, which roughly correspond to Protégé frames Instances, Slots and Classes. The process of ontology building is as following:

1) Using Create Class Hierarchy to create classes

2) Define Class property. The property consists in Functional, Inverse Functional, Transitive, Symmetric, Asymmetric, Reflexive, Irreflexive.

3) Define the Domains and Ranges of Property.

4) Describe and Define Classes using property.

5) Create and describe Individuals using restrictions. OWL restrictions in OWL fall into three main categoriesQuantifier, Cardinality, hasValue. The Quantifier restrictions can be further categorized into existential restrictions and universal restrictions.

6) Using A reasoner which is sometimes called classifiers.

In GEOBIA approaches, remote sensing images are segmented into homogeneous regions which are characterized by a set of spectral, spatial and topological features.

General information is formalized in a domain ontology using OWL ontology. It is shown in figure 7.

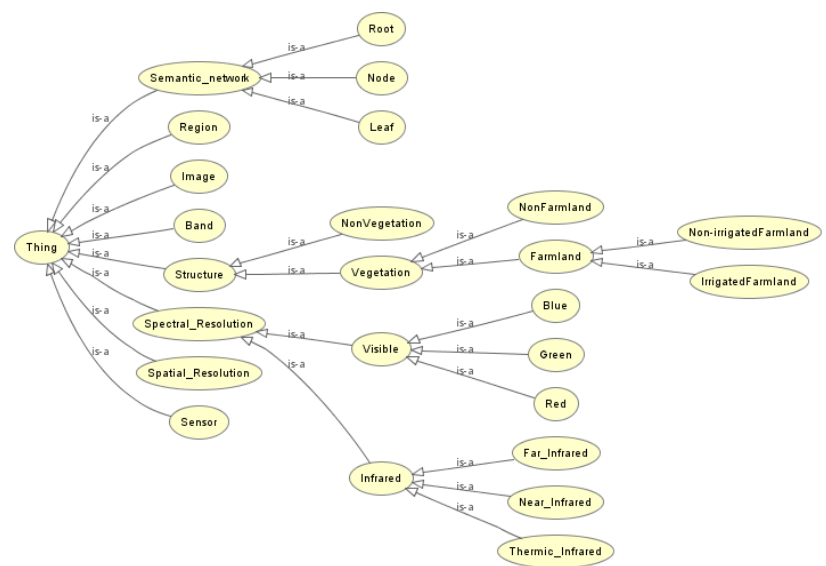

Figure 7 Farmland semantic network model in the ontology

In GEOBIA approaches, the image object individuals can be created by style conversion. The CSV style of image object can be converted to OWL style using XSLT. The features of image object are inserted into original OWL to form new OWL.

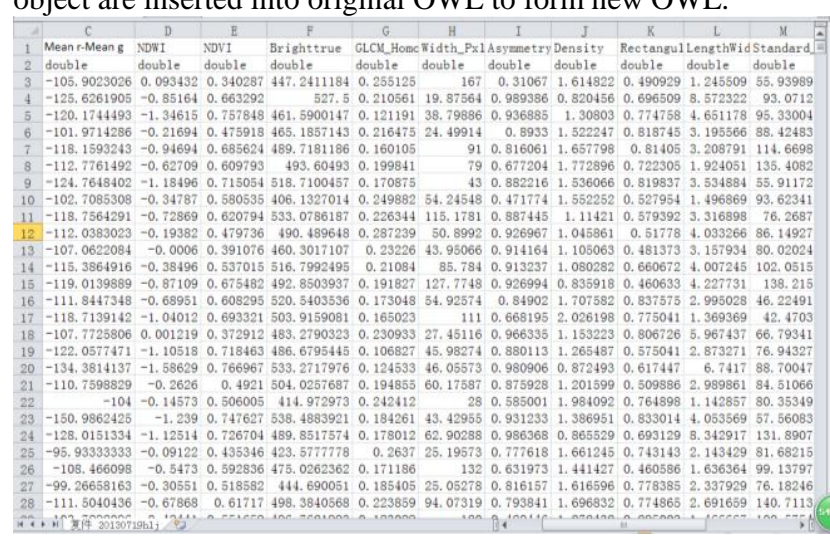

Figure 8. Feature table in csv style.

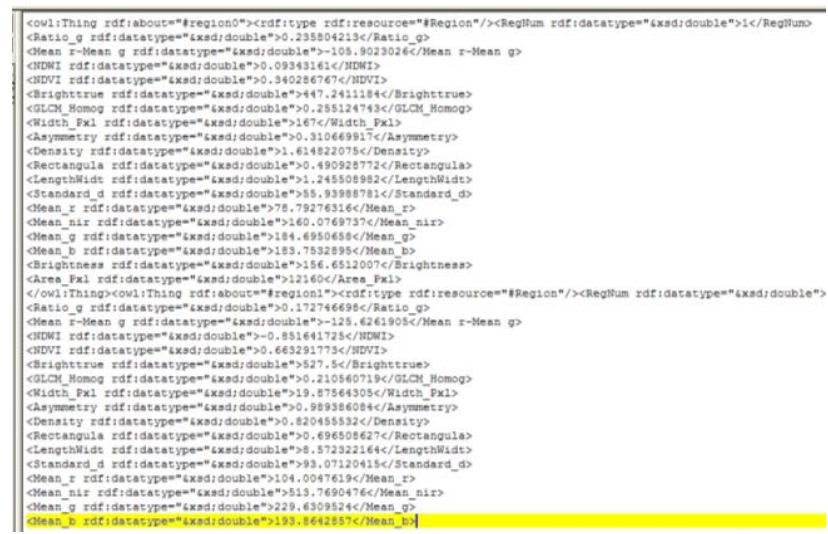

Figure 9. Feature in OWL style.

\subsection{Farmland Classification}

Under the guidance of Farmland ontology, the workflow of farmland classification based on semantic network model and hybrid learning is as followings: 


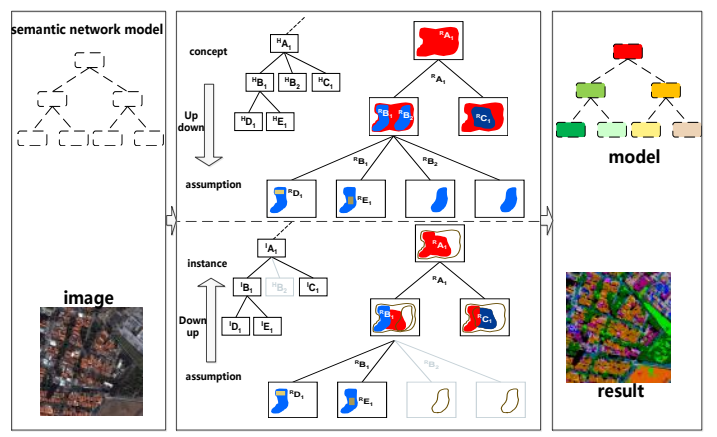

Figure 10. The workflow of farmland classification based on semantic network model and hybrid learning (A、B、C、

D、E stand for Class, ${ }^{\mathrm{H}} \mathrm{A}_{1}$ stands for the assumptions of Class

$\mathrm{A},{ }^{\mathrm{I}} \mathrm{A}_{1}$ stands for the instances of Class $\mathrm{A}$ )

There are two main steps:

Step1: Top-down production process: The image is classified based on Top-down operators (such as segmentation, classification, etc.) and decision rule (such as logical expressions, member functions, etc.). The process is associated with semantic network node, and its output is the object's assumption. Because these processes do not communicate with each other directly, they will produce inconsistent result. For example, the same geographic objects may have different object classes.

1) A is implemented with top-down operator.

2) The masks of $B$ and $C$ are created with top-down operator to generate assumptions of $\mathrm{B}$ and $\mathrm{C}$.

3) The masks of D and E are created with top-down operator to generate assumptions of $\mathrm{B}$ and $\mathrm{C}$.

Step2: Down -Top determination process:

The assumptions are validated with down-top decision rule (such as spatial decomposition, object merge). Assumptions become to the object instances after the end of interpretation.

1) Implement sub-class of $B$ with decision rules to produce the instances of $\mathrm{D}$ and $\mathrm{E}$.

2) Implement sub-class of A with decision rules to produce the instances of $\mathrm{B}$ and $\mathrm{C}$.

3) The instances of A are generated by comprehensive analysis.

\section{CONCLUSIONS AND FUTURE WORK}

This paper puts forward a framework for GEOBIA based on geographic ontology theory, which could implement " Geographic entities - Image objects - Geographic objects " true reappearance. The geographical object is described by geographic ontology, the semantic network model is built based on OWL, an image object is classified based on hybrid learning.

The new framework has the following advantages: (1) It could provide interpretation strategies and global framework for GEOBIA with the property of objective, overall, universal, universality, etc.; (2) It uses geo-ontology to link image objective characteristics and subjective knowledge experts, which could avoid inconsistencies caused by different experts' experience. (3) It could express objective concept, feature, and relationship obviously, and reduce the semantic gap between low-level features and high-level features, and is easy to articulate semantic relations in computer operable formal language; (4) It uses hybrid learning with up to down model and down to up model in the cognitive interpretation mode, which could not only reflect the geographical objects of remote sensing image interpretation results, but also verify and validate the semantic network model, and it could provide a reference model for similar area and similar data.

Research on geographic ontology-driven GEOBIA model is a new direction in the field of remote sensing image analysis, yet few people involved in it. Therefore, the paper is a try and preliminary research, which need more scholars, especially those with a strong background in geoscience. Thus this framework and model will have a broader recognition and application, and have great significance in the sharing and application of GEOBIA.

Furthermore, we will apply the framework in farmland extracting to further verify the feasibility of the framework, and to strengthen the research and application of GEOBIA models.

\section{ACKNOWLEDGEMENTS}

This research was funded by non-profit industry project "Research and application of surveying and mapping production technology (201412008)".

\section{REFERENCES}

Addink, E.A., Van Coillie, F.M.B., De Jong, S.M. 2012. Introduction to the GEOBIA 2010 special issue: from pixels to geographic objects in remote sensing image analysis. Int. J. Appl. Earth Obs. Geoinf. 15, pp.1-6.

Arvor, D., Durieux, L., Andres, S., et al. 2013. Advances in Geographic Object-Based Image Analysis with ontologies: A review of main contributions and limitations from a remote sensing perspective. ISPRS Journal of Photogrammetry and Remote Sensing, 82, pp.125-137.

Andres, S., Arvor, D., Pierkot, C. 2012. Towards an ontological approach for classifying remote sensing images. In: Signal Image Technology and Internet Based Systems (SITIS), IEEE, 2012 Eighth International Conference, pp.825-832.

Agarwal, P., 2005. Ontological considerations in GIScience. International Journal of Geographical Information Science, 19, pp.501-536.

Belgiu, M., Tomljenovic, I., Lampoltshammer, T. J., Blaschke, T., \& Höfle, B. 2014. Ontology-based classification of building types detected from airborne laser scanning data. Remote Sensing, 6(2), pp.1347-1366.

Belgiu, M., Hofer, B., Hofmann, P. 2014. Coupling formalized knowledge bases with object-based image Analysis. Remote Sensing Letters, 5(6), pp.530-538.

Blaschke, T., Hay, G.J., Kelly, M., Lang, S., Hofmann, P., Addink, E., Feitosa, R., Van Der Meer, F., Van Der Werff, H., Van Coillie, F., Tiede, D., 2014. Geographic object-based image analysis: a new paradigm in remote sensing and geographic information science. ISPRS J. Photogramm.Remote Sens. 87(1), pp.180-191.

Blaschke, T., Hay, G.J., Weng, Q., Resch, B., 2011. Collective sensing: integrating geospatial technologies to understand urban systems - an overview. Remote Sens. 3, pp.1743-1776.

Blaschke, T. 2010. Object based image analysis for remote sensing. ISPRS J. Photogramm. 65, pp.2-16.

Cui, W., Tang, S.M., Li, R., Yao, Z.W. 2013. A method of identifying remote sensing objects by using geo-ontology and 
relative elevation. Journal of Wuhan university of technology. 37(4), pp.695-698.

Dejrriri, K., Malki, M. 2012. Object-based image analysis and data mining for building ontology of informal urban settlements. Proc. SPIE 8537, Image and Signal Processing for Remote Sensing XVIII, 85371I.

Forestier, G., Puissant, A., Wemmert, C., et al. 2012. Knowledge-based region labeling for remote sensing image interpretation. Computers, Environment and Urban Systems, 36(5),pp.470-480.

Guan, X.L., Fang, C.L., Lu, S.S. 2010, Analysis of spatial distribution and gravity centers curve dynamic cultivated land changes in China. Journal of natural resources. 25(12), pp.1997-2006.

Gruber, T.R. 1993. A translation approach to portable ontology specifications. J. Knowl. Acquis. Knowl.-Based Syst. 5, pp.199-220.

Hay, G.J., Castilla, G. 2008. Geographic Object-Based Image Analysis (GEOBIA): A New Name for a New Discipline. In Object-Based Image Analysis: Spatial Concepts for Knowledgedriven Remote Sensing Applications; Blaschke, T., Lang, S., Hay, G.J., Eds.; Springer-Verlag: New York, NY, USA, pp. 8192.

Hussain, M., Chen, D.M.; Cheng, A.; Wei, H. Stanley, D. 2013.Change detection from remotely sensed images: From pixel-based to object-based approaches. ISPRS J. Photogramm. 80, pp. 91-106.

Jesús, M. A.-J., Luis, D., José A. P.-F.. 2013. A Framework for Ocean Satellite Image Classification Based on Ontologies. IEEE Journal of selected topics in applied earth observations and remote sensing,6(2), pp.1048-1063.

Kyzirakos, K., Karpathiotakis, M., Garbis, G. et al. 2014. Wildfire monitoring using satellite images, ontologies and linked geospatial data. Web Semantics: Science, Services and Agents on the World Wide Web, 24, pp.18-26.

Lüscher, P., Weibel, R., Burghardt, D. 2009. Integrating ontological modelling and Bayesian inference for pattern classification in topographic vector data. Comput. Environ. Urban Syst. 33, pp.363-374.

Mark, D.M., Smith, B., Egenhofer, M.J., Hirtle, S.C., 2005. Ontological foundations for geographic information science. In: McMaster, R.B., Usery, E.L. (Eds.), A Research Agenda for Geographic Information Science. CRC Press, Boca Raton, FLA.

Nussbaum, S., Menz, G. 2008. Object-Based Image Analysis and Treaty Verification: New Approaches in Remote SensingApplied to Nuclear Facilities in Iran; Springer-Verlag: New York, NY, USA.

Pu, R., Landry, S., Yu, Q. 2011. Object-based urban detailed land-cover classification with high spatial resolution IKONOS imagery. Int. J. Remote Sens. 32, pp.3285-3308.

Wei Y.Z., Deng N.R.,Wu Z.F., Gao Y., Chai M, 2008. Effects of Topography on Distribution and Change of Farmland in Mountainous Area of North Guangdong Province, China, Journal of mountain science, 26(1), pp.76-83.
Wiki.GEO-Object-Based image analysis; Available online: http://wiki.ucalgary.ca/page/GEOBIA (accessed on 5 May 2013).

Yue, P., Di, L., Wei, Y., Han, W., 2013. Intelligent services for discovery of complex geospatial features from remote sensing imagery. ISPRS Journal of Photogrammetry and Remote Sensing ,83,pp.151-164.

http://protege.stanford.edu 